\title{
ANALISIS PEMASARAN KOPI DI KECAMATAN BERMANI ULU RAYA KABUPATEN REJANG LEBONG
}

\section{(Analysis of Coffee Marketing in Bermani Ulu Raya Subdistrict, District} Rejang Lebong)

\author{
Sri Sugiarti \\ Jurusan Sosial Ekonomi Pertanian \\ Fakultas Pertanian Universitas Bengkulu
}

\begin{abstract}
The objectives of the research are to study coffee marketing system and to analyze marketing margin in Bermani Ulu Raya district. From these objectives, marketing structure and market behaviorthat reflect a coffee marketing efficiency in Bermani Ulu Raya district can be examined. The result showed that coffee marketing system in the Bermani Ulu Raya is inefficient as indicated by small share margin at frm level and big share marketing margin at following marketing channels. The research also showed that coffee market can be categorized as olygopsonistic market especially wholesaler level.
\end{abstract}

Key words : Coffee, Marketing, Margin

\section{PENDAHULUAN}

Komoditas kopi di Bengkulu menempati posisi utama sebagai komoditas ekspor,dimana areal tanaman kopi sekitar 86.370 hektar yang hampir 100\% merupakan perkebunan rakyat. Dari jumlah areal tersebut $56,52 \%$ diusahakan di kabupaten Rejang Lebong (BPS Bengkulu,2005).

Beberapa masalah pokok yang dihadapi pada perkopian di Bengkulu adalah : 1) Rendahnya Produktivitas; 2) Rendahnya mutu hasil dan 3) Rendahnya Harga Jual Ditingkat Petani. Selama produksi dari tahun 2001 sampai dengan 2005 produksi rata-rata per hektar sebesar $457 \mathrm{Kg}$ masih tergolong rendah dibawah produksi rata-rata daerah Lampung yaitu 761 $\mathrm{Kg} /$ Hektar. Hal ini disebabkan penggunaan varitas robusta local, cara bercocok tanam yang masih tradisional, pengeringan kopi belum sepenuhnya menggunakan lantai jemuran, pengupasan kulit kopi sebagian besar menggunakan huller atau ditumbuk yang memperbesar presentase biji pecah dan sebagainya. 
Selain masalah produksi, masalah lain yang tidak kalah pentingnya adalah masalah pemasaran hasil kopi. Masalah-masalah pemasaran kopi di Bengkulu antara lain adalah : 1) Hubungan harga yang diterima petani dengan biaya produksi yang mungkin tidak merangsang petani untuk meningkatkan produksi baik jumlah dan mutu; 2) Margin pemasaran yang relatif tinggi dan kemungkinan fasilitas pemasaran yang belum memadahi untuk memperlancar arus komoditas.

\section{METODE PENELITIAN}

Penelitian ini dilakukan di desa Babakan Baru dan Air Bening merupakan desa penghasil produksi kopi yang tinggi di kecamatan Bermani Ulu Raya kabupaten Rejang Lebong.

Metode penelitian yang digunakan dalam penelitian adalah metode survey. Populasi yang dijadikan responden dalam penelitian ini dilakukan mereka yang mempunyai perkebunan kopi dan mengolah sendiri di desa-desa yang terpilih sebagai desa penelitian. Dari 400 petani, 75 petani kopi dipilih sebagai sampel dengan metode simple random sampling. Pemilihan lembaga pemasaran sebagai responden dilakukan secara sensus.

Data yang diambil dalam penelitian ini yaitu bersumber dari data primer dan data sekunder. Dua metode analisa digunakan yakni analisis kualitatif maupun kuantitatif.Analisis kualitatif mengamati secara langsung keadaan sistem pemasaran kopi dikecamatan tersebut dan analisis kuantitatif digunakan untuk melihat sebaran margin pemasaran.

Analisis margin pemasaran kopi pada masing-masing lembaga pemasaran dilakukan analisis kuantitatif secara matematis (Azzaino,1983) sebagai berikut :

$\mathrm{Mji}=\mathrm{Psi}-\mathrm{Pbi}$

$$
\begin{aligned}
& \prod I=M j i-B t i \\
& M j=\sum M j i
\end{aligned}
$$

$\mathrm{Mji}=\mathrm{Bti}+\prod \mathrm{i}$

Dimana :

Mji adalah margin pemasaran pada lembaga pemasaran ke i.

Psi adalah harga jual pemasaran tingkat kei.

Pbi adalah harga beli lembaga pemasaran ke i.

Bti adalah biaya pemasaran tingkat i.

ПI adalah keuntungan pemasaran tingkat i.

$\mathrm{Mj}$ adalah total margin pemasaran. 


\section{HASIL DAN PEMBAHASAN}

\section{Saluran Pemasaran}

Kegiatan pemasaran kopi sebagai suatu rangkaian kegiatan yang menyalurkan kopi beserta hasil olahannya, mulai dari petani produsen sampai kepada konsumen.Untuk beberapa daerah seperti kecamatan Bermani Ulu Raya merupakan suatu kegiatan pemasaran hasil kopi yang cukup penting.Untuk komoditas kopi, di desa Babakan Baru dan desa Air Bening merupakan penghasil terbesar di kecamatan Bermani Ulu Raya.

Ada satu pola saluran pemasaran kopi yang umum di kecamatan Bermani Ulu Raya yaitu saluran pemasaran untuk konsumsi didaerah produksi yaitu untuk pasar eceran lokal dan industri pengolah didaerah produksi.Gambar 1 memperlihatkan saluran pemasaran kopi didesa penelitian ke konsumen.

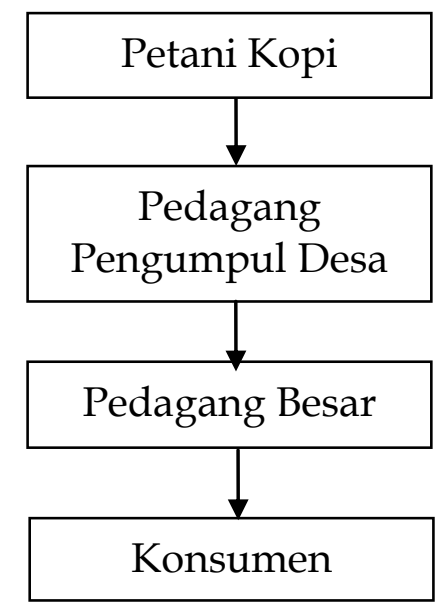

Gambar 1. Saluran pemasaran kopi di Kecamatan Bermani Ulu Raya

Dari gambar diatas dapat dilihat pedagang perantara pertama dalam saluran pemasaran adalah pedagang pengumpul desa sebanyak 4 orang dengan jumlah pembelian per bulan rata-rata $29.500 \mathrm{Kg}$ dalam bentuk biji yang sudah kering.Sebelum kopi tersebut dijual petani terlebih dahulu melakukan penggilingan di heler.Selanjutnya dari pedagang pengumpul desa dijual kepedagang besar jumlahnya sebanyak 2 orang dengan jumlah pembelian pasar per bulan rata-rata $59.000 \mathrm{Kg}$. dari pedagang besar dijual ke konsumen (pedagang pengecer/pedagang luar daerah). 


\section{Struktur Dan Tingkah Laku Pasar}

Hubungan antara petani dengan pedagang,bahwa petani hanya mempunyai 1 kemungkinan untuk memasarkan hasil produksinya yaitu menjual kepada pedagang pengumpul desa. Dalam penjualan dengan cara melakukan terlebih dahulu penjemuran biasanya 4 - 8 hari atau tergantung dengan cuaca baru dijual ke pedagang pengumpul desa. Mengenai harga ditetapkan berdasarkan per $\mathrm{Kg}$ dari hasil panen yang nyata.

Hubungan antara pedagang pengumpul desa dan pedagang besar, disini pedagang pengumpul desa terjadi proses pengolahan kopi dari biji kering ke penggilingan atau pengupasan kulit di heler. Selanjutnya pedagang desa menjual kopi yang sudah digiling kepedagang besar, dan tingkat harga yang ditetapkan berdasarkan per $\mathrm{Kg}$ dari hasil penggilingan.Besarnya biaya pengolahan, pengangkutan dapat dilihat pada tabel 1.

Hubungan antara pedagang besar dengan konsumen, rata-rata telah mempunyai hubungan yang kontinyu dan sudah sejak lama.Pedagang besar ini membeli dan menyimpan kopi dalam jumlah sebanyak mungkin disesuaikan dengan kemampuannya.Disamping itu pedagang besar bisa memperkirakan adanya kenaikan harga kopi lebih dahulu.

Tabel 1. Rata-rata biaya pemasaran kopi didaerah penelitian

\begin{tabular}{|c|c|c|c|c|}
\hline \multirow{2}{*}{ Jenis biaya } & \multicolumn{2}{|c|}{$\begin{array}{c}\text { Pedagang Pengumpul } \\
\text { Desa }\end{array}$} & \multicolumn{2}{|c|}{ Pedagang besar } \\
\hline & $\begin{array}{c}\text { Biaya } \\
(\mathrm{Rp} / \mathrm{Kg})\end{array}$ & $\begin{array}{c}\text { Persentase } \\
(\%)\end{array}$ & $\begin{array}{c}\text { Biaya } \\
(\mathrm{Rp} / \mathrm{Kg})\end{array}$ & $\begin{array}{c}\text { Persentase } \\
(\%)\end{array}$ \\
\hline 1. Penyusutan Alat & 0,37 & 0,05 & 2,13 & 0,07 \\
\hline 2. Pengemasan & & & & \\
\hline a. Karung & 0 & 0 & 54,50 & 1,86 \\
\hline b. Tali & 0 & 0 & 14 & 0,48 \\
\hline c. Kantong & 0 & 0 & 26 & 0,89 \\
\hline $\begin{array}{l}\text { Plastik } \\
\text { d. Isi Necis }\end{array}$ & 0 & 0 & 13 & 0,44 \\
\hline 3. Transportasi & 131,25 & 18 & 0 & 0 \\
\hline 4. Tenaga Kerja & 47,5 & 6,51 & 52,5 & 1,79 \\
\hline 5. Sewa Gudang & 0 & 0 & 122 & 4,16 \\
\hline 6. Susut Kopi & 500 & 75,43 & 2650 & 90,32 \\
\hline Jumlah & 729,12 & 100 & 2934,13 & 100 \\
\hline
\end{tabular}

Sumber : Data Primer Yang Diolah, 2007 
Berdasarkan Tabel 1 dapat diketahui bahwa pedagang pengumpul desa dan pedagang besar mengeluarkan biaya pemasaran seperti biaya transportasi, penyusutan, tenaga kerja, pengemasan dan penyusutan kopi.

\section{Analisis Margin}

Analisis margin pemasaran kopi dari tingkat usaha tani dikecamatan Bermani Ulu Raya ke konsumen menunjukkan bahwa petani menerima 37,92\% dari harga yang dibayarkan konsumen apabila menjual dalam cara Kilogram dapat dilihat pada tabel 2 .

Harga jual yang diterima sebesar Rp 13.250 per Kg sehingga diperoleh tambahan sebesar Rp 1.270,88 per Kg.Bila ditelaah lebih lanjut maka margin pemasaran yang paling besar terdapat pada pedagang besar Rp 16.750 per $\mathrm{Kg}(55,83 \%)$ dari harga eceran seperti dapat dilihat pada tabel 2. Besarnya margin ditingkat ini disebabkan tingginya keuntungan yang diperoleh pedagang besar. Sedangkan biaya pemasaran terbesar dikeluarkan oleh pedagang besar dimana terjadi proses pengolahan dari biji kering menjadi kopi bubuk. Pedagang besar ini mampu mengadakan perkiraan tentang situasi produksi dan konsumsi, sehingga dapat menentukan tingkat harga yang paling menguntungkan bagi mereka hal ini dapat dilakukan karena adanya struktur pasar yang bersifat oligopsoni pada tingkat lembaga ini.

Pedagang pengumpul desa memperoleh keuntungan yang terkecil yaitu $1.270,88$ per $\mathrm{kg}$ atau $4,24 \%$ dari harga eceran. Hal ini disebabkan pedagang pengumpul desa telah menerima patokan harga yang besarnya telah ditentukan pedagang besar, sedangkan mereka harus bersaing dengan sesame pedagang pengumpul desa lainnya dalam melakukan pembelian kopi dari petani.Walaupun jumlah pedagang pengumpul desa jumlahnya 4 orang peneliti menganggap bahwa struktur pasar kopi pada tingkat pedagang pengumpul desa adalah bersaing sempurna.

Analisis margin pemasaran kopi didesa penelitian kecamatan Bermani Ulu Raya menunjukkan sebagian kecil dari harga yang dibayarkan konsumen diterima oleh petani yaitu 37,92\% dapat dilihat tabel 2. Penyebaran margin, biaya dan keuntungan pada tiap tingkat lembaga pemasaran kurang merata, margin pemasaran terbesar terdapat pada pedagang besar yaitu Rp 16.750 per $\mathrm{Kg}$ atau 55,83\% dari harga eceran. Besarnya margin pada tingkat lembaga ini disebabkan oleh tingginya keuntungan yang diperoleh yaitu sebesar 13.815,87 atau $46,06 \%$ dari harga eceran. 
Tabel 2. Analisis Rata-rata margin pemasaran kopi didaerah penelitian

\begin{tabular}{lcc}
\hline \multicolumn{1}{c}{ Uraian } & $\mathbf{R P} / \mathbf{K g}$ & Share (persentase) \\
\hline 1. Petani & 11.375 & 37,92 \\
Harga Beli & & \\
2. Pedagang Pengumpul Desa & 11.375 & 37,92 \\
a. Harga Beli & 729,12 & 2,43 \\
b. Total Biaya & 2000 & 6,67 \\
c. Margin & 1270,88 & 4,24 \\
d. Keuntungan & 13.250 & 44,17 \\
e. Harga Jual & & \\
3. Pedagang besar & 13.250 & 44,17 \\
a. Harga beli & $2.934,13$ & 9,78 \\
b. Total Biaya & 16.750 & 55,83 \\
c. Margin & $13.815,87$ & 46,05 \\
d. Keuntungan & 30.000 & 100 \\
e. Harga Jual & & $\mathbf{1 2 , 2 1}$ \\
\hline Total & $\mathbf{3 . 6 6 3 , 2 5}$ & $\mathbf{6 2 , 5}$ \\
Biaya pemasaran & $\mathbf{1 8 . 7 5 0}$ & $\mathbf{5 0 , 2 9}$ \\
Margin & $\mathbf{1 5 . 0 8 6 , 7 5}$ & \\
Keuntungan & & \\
\hline Subr : Data Primer & & \\
\hline
\end{tabular}

Sumber : Data Primer Diolah, 2007

Penyebaran margin, biaya dan keuntungan pada tiap tingkat lembaga pemasaran kurang merata seperti terlihat pada tabel 2, margin pemasaran terbesar terdapat pada pedagang besar yaitu Rp 16.750 per Kg atau 55,83\% dari harga eceran. Besarnya margin pada tingkat lembaga ini disebabkan oleh tingginya keuntungan yang diperoleh yaitu sebesar 13.815,87 atau 46,06\% dari harga eceran.

\section{SIMPULAN DAN SARAN}

\section{Simpulan}

Sistem pemasaran kopi di kecamatan Bermani Ulu Raya telah bekerja kurang efektif, artinya dapat menyalurkan kopi yang dihasilkan dari tingkat petani ke tingkat konsumen dengan lancer tetapi pasar dimana lembaga pemasaran kopi bekerja adalah oligopsoni pada tingkat pedagang besar didaerah konsumsi. 
Sistem pemasaran kopi dikecamatan Bermani Ulu Raya telah berjalan kurang efisien. Hal ini ditunjukkan rendahnya bagian harga yang diterima petani dan penyebaran margin,biaya dan keuntungan yang belum merata pada tingkat lembaga pemasaran.

\section{Saran}

Agar efisiensi pemasaran kopi tercapai, perlu adanya pemberian informasi yang lebih luas untuk semua lembaga yang terlibat dalam sistem pemasaran. Informasi ini meliputi informasi tentang arus barang,tempat penjualan, kerusakan fisik dan lain-lain.

\section{DAFTAR PUSTAKA}

Azzaino,Z,1982.Pengantar Tataniaga Pertanian. Departemen Ilmu-Ilmu Sosial Ekonomi Pertanian Fakultas Pertanian IPB Bogor.

Arifin Rudianto,1984.Analisis Pendekatan Sistem Pemasaran Kacang-Kacangan Di Jawa Timur. Jurusan Ilmu-Ilmu Sosial Ekonomi Pertanian Fakultas Pertanian IPB Bogor.

Elis Syahniah,2008.Analisis Pendapatan Dan Pemasaran Kopi Di Desa Babakan Baru Dan Desa Air Bening Kecamatan Bermani Ulu Raya Kabupaten Rejang Lebong. Skripsi Fakultas Pertanian UNIB.

Hernanto,F,1989.Ilmu Usaha Tani. Penebar Swadaya Jakarta.

Saeffuddin A.M.,1982.Pemasaran Produk Pertanian IPB Bogor.

Surahtiah,Ken,2006.Ilmu Usaha Tani. UGM Yogyakarta.

Swasta B,1972.Asas-Asas Marketing. Liberty Yogyakarta. 